\title{
Relationship between Teacher Effectiveness and Quality of Work Life
}

\author{
Minal R. Thakur ${ }^{1}$ and Indu Garg ${ }^{2}$
}

${ }^{1}$ Ph.D Research Scholar, Department of Education, University of Mumbai, Vidya Nagari, Kalina, Mumbai, Maharashtra, India ${ }^{2}$ Former HOD, Department of Education, University of Mumbai, Vidya Nagari, Kalina, Mumbai, Maharashtra, India

*Corresponding author: thakurminal26@yahoo.in

Received: 10-03-2020 Revised: 12-06-2020 Accepted: 25-07-2020

\begin{abstract}
This paper is an attempt to present an analysis of Teacher Effectiveness and its correlation with the Quality of their Work Life. Educators (teachers) have been considered as an impetus for various social reformations that take place in a cohesion. Teaching,even today is a noble profession and teacher an epitome of nobility. With the new education policy announced by the Indian government, status of the teacher would further be reinstated as an esteemed and indispensable element of the society. Teachers play a pivotal role in shaping the future of the country and therefore it is important to empower them to carry out their responsibilities effectively. Teachers, being idolized by many, need to be effective, present high quality standards and set a benchmark for others to follow. The purpose of conducting this study was to know whether teacher effectiveness / ineffectiveness ameliorates the quality of their work life. Teacher Effectiveness means professional commitment and teachers' sense of responsibility in executing instructions assessing her mental, physical and emotional health. Teacher effectiveness affects the quality of their work life which is considered - a process by which an organization responds to teachers need allowing them to design their lives at work. The present study used the correlational method to assess the statistical relationship between the two variables - Teacher Effectiveness and Quality of Work Life. The sample of 393 teachers from English Medium Schools of Greater Mumbai was considered for the study. The findings of the study highlights a significant low relationship between the variables Teacher Effectiveness and Quality of Work life.
\end{abstract}

Keywords: Teacher Effectiveness, Quality of Work Life, Cohesion, Indispensable

Education is an anchorage upon which a country's economy rests and teacher an anchor of the very existence of the educational system. The goal of any educational system is to emphasis the development of cognitive and creative domains of its stake holders. To carry out the herculean task that encompasses the creation of an educated generation it is important to empower teachers.

Effective teachers can create effective global leaders (citizens) for which teachers themselves have to be effective in every sphere of their profession. Effective teachers play a significant role in creating world class scholastic and non-scholastic performers. Effective teachers strive to attain goals which they have set for themselves and which others have set for them.
So, the question that one needs to ponder upon is, what type of a person should a teacher be in order to be effective? This question is important as it throws light on the significant aspect of teacher effectiveness and the quality of their work life. An effective teacher would work $24 / 7$ to enhance the quality of her work life.

Quality of work life is therefore understood as a multidimensional concept. Its main aim is to improve productivity assuring the well-being of its employees at the same time. It is concerned majorly

How to cite this article: Thakur, M.R. and Garg, I. (2020). Relationship between Teacher Effectiveness and Quality of Work Life. Educational Quest: An Int. J. Edu. Appl. Soc. Sci., 11(2): 121-124.

Source of Support: None; Conflict of Interest: None (क) ब 
with improvement of life not only at work but also off work.

This research was therefore undertaken with the purpose to know: (1) Effectiveness of teachers falling in the age group of 23 to 30 years, with experience of 6 months to 5 years. (2) Whether teacher effectiveness determines the quality of their work life.

\section{Need for the Study}

Considering the current scenario of the society teachers are the under - valued class. Teaching does not provide with the required finance to adopt a desired life style. The craze to be modern and follow latest trends has given rise to innumerable desires which cannot be full filled by the earnings that, teaching job offers. Hence, teachers have developed a very casual attitude towards work. This has deteriorated their work quality.

The present generation is tech savvy and society is changing from being agrarian to digital. This shifting trend to digitalization has led to reverse mentoring in teachers. Teachers have to learn technology from children which has further lowered their efficiency, effectiveness and quality.

Review of related literature provides with persuasive evidence that, the combination of variables selected for the present study, has not been adequately attempted so far in the field of education. Hence the need for the present study was felt.

\section{Statement of the Problem}

The problem of the study has been stated as:

A Study of Relationship between Teacher Effectiveness and Quality of Work Life.

\section{Variables of the Study}

1. Teacher Effectiveness

2. Quality of Work Life

\section{Definitions of the Variables}

\section{Teacher Effectiveness}

Teacher Effectiveness can be defined as teacher's ability of planning and presentation of the task given at hand, her professional commitment and sense of responsibility, her ways of executing instructions keeping in view her mental, physical and emotional health and her relationship with the educational setup and society.

Teacher effectiveness has been studied under following components:

1. Preparation and Planning

2. Classroom Management

3. Knowledge of Subject Matter

4. Teachers' Characteristics

5. Interpersonal Relationship

\section{Quality of Work Life}

Quality of work life is a process of organizing one's work in a way in which it ensures physical, social, economic, psychological and cultural wellbeing of its teachers. It is a building block on which a satisfying life can be built meeting the twin goal of enhanced effectiveness of the institution and improved quality of work life for teachers.

The Quality of Work Life has been studied under the following components:

1. Adequate and Fair Compensation

2. Safe and Healthy Working Conditions

3. Development of Human Capacities

4. Growth and Security

5. Social Integration

6. Constitutionalism

7. Total Life Space

8. Social Relevance

\section{Objective of the Study}

The study was undertaken with the following objective:

To ascertain the relationship between teacher effectiveness and quality of work life of school teachers.

\section{Hypothesis of the Study}

The null hypothesis formulated for the study is stated as follows:

There is no significant relationship between teacher effectiveness and quality of work life of school teachers. 


\section{Research Design}

\section{Methodology of the Study}

In the present study correlational method has been used precisely to measure the extent to which the two variables are related to each other. The data collection involved gathering quantitative data by using standardized tools. The data thus collected were analyzed using appropriate statistical techniques.

\section{Sample of the Study}

In the present study, the sample comprised of 393 teachers from English Medium Schools of Greater Mumbai. The teachers falling in the age group of 23 to 30 years and with 6 months to 5 years of experience were considered for the study. The sample therefore comprised of 40 male and 353 female teachers.

\section{Tools of Data Collection}

The following tools were used for data collection:

1. Teacher Effectiveness Scale developed by Umme Kulsum.

2. Quality of Work Life Scale based on Walton's quality of work life model.

\section{Delimitations of the Study}

The study under consideration was restricted to the teachers of English medium schools of Greater Mumbai. It considered the said variables and covered only those teachers falling in the age group of 23 to 30 years and having experience of 6 months to 5 years.

\section{Testing of the Hypothesis}

The hypothesis states that there is no significant relationship between teacher effectiveness and quality of work life of school teachers.

Technique used: Pearson's Product Moment Coefficient of Correlation (' $r$ ').

\section{Findings and Conclusion}

Table 1 shows the statistics of correlation between the variables teacher effectiveness and quality of work life. A significant low relationship has been found between the two variables as per the tabulated range of correlation and hence the null hypothesis is rejected. Since ' $r$ ' is positive it suggests a direct positive linear relationship between the two variables under study. Since the value of ' $r$ ' ranges between +1 and -1 , the obtained ' $r$ '. .231 is closer to 0 indicating low but significant relationship between two variables.

Table 1: Coefficient of Correlation (' $r$ ') between Teacher Effectiveness and Quality of Work Life

\begin{tabular}{llllll}
\hline Variables & Group & $\mathbf{N}$ & 'r' & $\begin{array}{l}\text { Df } \\
(\mathbf{n}-2)\end{array}$ & LOS \\
\hline $\begin{array}{l}\text { Teacher } \\
\text { Effectiveness }\end{array}$ & $\begin{array}{l}\text { Total } \\
\text { sample }\end{array}$ & 393 & .231 & 391 & S \\
$\begin{array}{l}\text { Quality of Work } \\
\text { Life }\end{array}$ & & & & $(0.01)$ \\
\hline
\end{tabular}

\section{DISCUSSION}

It can be inferred from the findings that there exists a positive correlation between teacher effectiveness and quality of work life though the relationship is low. Low relationship could be due to the fact that teachers face various crisis in their profession in particular when they are having less of work experience. Further, being effective and ineffective affects their work quality to a greater extent. Teachers' characteristics, her ability to manage the classroom well, her ability to plan interest arresting lessons, decide, the quality of her work life. If a teacher has mastery over her subject area she can make students take interest in her lessons. She can develop love for the subject that she teaches. Teacher quality matters and so does her effectiveness. In fact both these components are essential while designing an efficient education system.

It can therefore be concluded that teacher effectiveness is related to quality of work life of school teachers. The relationship can be low but it can bring about considerable changes in either of the variables.

\section{CONCLUSION}

It can be concluded that, teacher effectiveness influences teachers' quality of work life. Effective and quality teaching includes polishing competencies over and over again. It is important for a teacher to know her own strengths and weakness, her purpose of selecting the profession and her responsibilities towards the stakeholders. 


\section{REFERENCES}

Walton, R. 1975. Evaluation of Quality of Work Life: An Adaptation from Walton's Quality of Work Life Model. International conference on Industrial Engineering and operational management. Retrieved from www.abepro.org.br

Creswell, J.W. \& Plano Clark, V.L. 2011. Designing and Conducting Mixed Methods Research ( $\left.2^{\text {nd }} \mathrm{ed}\right)$. USA, Sage Publications, Inc.

Best, J.W. \& Kahn, J.V. (2006). Research in Education (9 ${ }^{\text {th }} \mathrm{ed}$ ). New Delhi, Prentice Hall of India Pvt. Ltd.

Dutt, N.K. 1974. Psychological Foundation of Education. New Delhi, Doabo House Publications.
Koul, L. 2005. Methodology of Educational Research (3 ${ }^{\text {rd }}$ ed). New Delhi, Vikas Publishing House Pvt. Ltd.

Pandya, S.R. 2010. Educational Research, New Delhi, A.P.H. Publishing Corporation.

www.refractivethinkers.com

www.classbase.com

www.simplypsychology.org

www.speakingtree.in/blog/indian-education-system

Blogs.discovermagazine.com/... 